\title{
Noisy Spiking in Visual Area V2 of Amblyopic Monkeys
}

\author{
ํㅏe Wang, ${ }^{1}$ Bin Zhang, ${ }^{2}$ ○Xiaofeng Tao, ${ }^{3}$ Janice M. Wensveen, ${ }^{1}$ Earl L. Smith $3 r d,{ }^{1}$ and Yuzo M. Chino ${ }^{1}$ \\ ${ }^{1}$ College of Optometry, University of Houston, Houston, Texas $77204,{ }^{2}$ College of Optometry, NOVA Southeastern University, Fort Lauderdale, Florida \\ 33314, and ${ }^{3}$ Department of Ophthalmology, Baylor College of Medicine, Houston, Texas 77030
}

Interocular decorrelation of input signals in developing visual cortex can cause impaired binocular vision and amblyopia. Although increased intrinsic noise is thought to be responsible for a range of perceptual deficits in amblyopic humans, the neural basis for the elevated perceptual noise in amblyopic primates is not known. Here, we tested the idea that perceptual noise is linked to the neuronal spiking noise (variability) resulting from developmental alterations in cortical circuitry. To assess spiking noise, we analyzed the contrast-dependent dynamics of spike counts and spiking irregularity by calculating the square of the coefficient of variation in interspike intervals $\left(\mathrm{CV}^{2}\right)$ and the trial-to-trial fluctuations in spiking, or mean matched Fano factor ( $\mathrm{m}$-FF) in visual area V2 of monkeys reared with chronic monocular defocus. In amblyopic neurons, the contrast versus response functions and the spike count dynamics exhibited significant deviations from comparable data for normal monkeys. The $\mathrm{CV}^{2}$ was pronounced in amblyopic neurons for highcontrast stimuli and the m-FF was abnormally high in amblyopic neurons for low-contrast gratings. The spike count, $\mathrm{CV}^{2}$, and $\mathrm{m}$-FF of spontaneous activity were also elevated in amblyopic neurons. These contrast-dependent spiking irregularities were correlated with the level of binocular suppression in these V2 neurons and with the severity of perceptual loss for individual monkeys. Our results suggest that the developmental alterations in normalization mechanisms resulting from early binocular suppression can explain much of these contrast-dependent spiking abnormalities in V2 neurons and the perceptual performance of our amblyopic monkeys.

Key words: amblyopia; macaque; spiking noise; stimulus contrast; visual area V2

\section{Significance Statement}

Amblyopia is a common developmental vision disorder in humans. Despite the extensive animal studies on how amblyopia emerges, we know surprisingly little about the neural basis of amblyopia in humans and nonhuman primates. Although the vision of amblyopic humans is often described as being noisy by perceptual and modeling studies, the exact nature or origin of this elevated perceptual noise is not known. We show that elevated and noisy spontaneous activity and contrast-dependent noisy spiking (spiking irregularity and trial-to-trial fluctuations in spiking) in neurons of visual area V2 could limit the visual performance of amblyopic primates. Moreover, we discovered that the noisy spiking is linked to a high level of binocular suppression in visual cortex during development.

\section{Introduction}

Experiencing double vision or chronic monocular defocus near birth initiates interocular decorrelation of cortical inputs, which in turn can lead to compromised binocular vision and amblyopia. Amblyopic primates lose fine spatial vision and contrast sensitivity and exhibit difficulties in a broad range of complex

Received Oct. 13, 2016; revised Dec. 2, 2016; accepted Dec. 10, 2016.

Author contributions:Y.W. and Y.M.C. designed research;B.Z., X.T., J.M.W., and Y.M.C. performed research;Y.W., B.Z., X.T., and Y.M.C. analyzed data; Y.W., B.Z., E.L.S., and Y.M.C. wrote the paper.

This work was supported by the National Institutes of Health (National Eye Institute) Research Grants R01 EY-008128 to Y.C. and R01 EY-003611 to E.L.S. and Core Grant P30 EY-007551. We thank Shinji Nishimoto of Osaka University for critical comments on the earlier draft of this manuscript.

The authors declare no competing financial interests.

Correspondence should be addressed to Yuzo Chino, Ph.D., College of Optometry, University of Houston, 4901 Calhoun Rd., Houston, TX 77204-2020. E-mail:ychino@uh.edu.

DOI:10.1523/JNEUROSCI.3178-16.2016

Copyright $\odot 2017$ the authors $\quad 0270-6474 / 17 / 370922-14 \$ 15.00 / 0$ perceptual tasks (for reviews, see McKee et al., 2003; Levi, 2008). Abnormal development in a population of neurons in the primary visual cortex (V1) is traditionally thought to be responsible for vision impairments in amblyopic primates (for reviews, see Kiorpes, 2006; Levi, 2013). However, decades of perceptual studies and intense focus on investigations of V1 have led to the rather surprising, but not extensively documented, view that a wide range of perceptual impairments in amblyopes may result largely from neural deficits in visual areas beyond V1 (Levi et al., 2008; El-Shamayleh et al., 2010; Bi et al., 2011; Farzin and Norcia, 2011; Tao et al., 2014; Shooner et al., 2015).

The vision of amblyopic humans is often described as being "noisy": abnormally enhanced noise in their visual system is thought to prevent amblyopic humans from reliably detecting or discriminating visual stimuli (Levi and Klein, 2003; Pelli et al., 2004; Xu et al., 2006; Levi et al., 2007, 2008). However, the exact nature and origin of such elevated perceptual noise are not 
known (Levi, 2013). One dominant idea is that amblyopes exhibit a high fraction of "internal (random) noise" (Levi et al., 2008; Levi, 2013). The neural basis for this sort of perceptual deficit has not been studied. In normal monkeys, spiking noise in extrastriate neurons (e.g., spike train irregularity, trial-to-trial fluctuations, and correlated noise) are thought to have a substantial influence on the reliability of neuronal coding and visual performance (Britten et al., 1992; Parker and Newsome, 1998; Shadlen and Newsome, 1998; Faisal et al., 2008; Churchland et al., 2010; Churchland and Abbott, 2012; Goris et al., 2014; Kohn et al., 2016).

In this study, we created a macaque model of amblyopia by raising infant monkeys with chronic monocular defocus that resulted in a range of anisometropic amblyopic deficits. We examined the central hypothesis that the abnormal dynamics of spike count, elevated spiking noise [square of the coefficient of variation in interspike intervals (ISIs), $\left.\mathrm{CV}^{2}\right]$, and a higher level of trial-to-trial fluctuations (mean matched Fano factor, m-FF), in visual area V2 are critical neural factors that can limit perception of amblyopic primates. We also tested the hypothesis that early abnormal binocular interactions, especially suppressive binocular interactions in V1 and V2, are closely linked to the emergence of noisy signal processing. Our studies show that the spiking of V2 neurons in our amblyopic monkeys is surprisingly robust but indeed noisy and that spiking noise is correlated with the strength of binocular suppression in these amblyopic neurons and with the perceptual impairments of individual monkeys.

\section{Materials and Methods}

Procedures. All experimental and animal care procedures were in compliance with the Guiding Principles for Research Involving Animals and were approved by the Institutional Animal Care and Use Committee of the University of Houston.

Subjects. The subjects were eight rhesus monkeys (Macaca mulatta); five males and three females. Three monkeys served as normally reared controls and five monkeys served as amblyopic subjects. Much of the data described here were obtained in the experimental monkeys in previous unrelated experiments (Tao et al., 2012, 2014; Zhang et al., 2013). The amblyopic monkeys were produced by rearing infant monkeys with an optically simulated anisometropia, a significant interocular difference in refractive errors. The procedures for creating anisometropia by optical means have been described previously in detail (Wensveen et al., 2003, 2006). Briefly, at 3 weeks of age (approximately equivalent to 3 months of age in humans), infant monkeys were fitted with a lightweight helmet that secured a defocusing lens in front of one eye and a plano lens in front of the other eye. The anisometropic lens powers were varied between -3 and $-10 \mathrm{D}$ based on each animal's refractive status at the start of the lens-rearing period. The goal was to produce an anisometropia that was not eliminated by compensating ocular growth (i.e., emmetropization) and that produced a mild to moderate degree of amblyopia. This rearing method has been proven to create moderate amblyopia reliably in macaque monkeys (Wensveen et al., 2003, 2006).

Around 18-24 months of age, behavioral testing began to measure the animals' monocular visual capacities. The basic apparatus and operant procedures have been described previously in detail (Wensveen et al., 2003, 2006; Tao et al., 2014). An amblyopia index and the spatial resolution (acuity) of each eye were calculated from contrast sensitivity functions. The amblyopia index ranged between 0.38 and 0.81 (see Fig. 9). Three monkeys exhibited "bilateral" amblyopia: the fellow eye also exhibited a significant loss of contrast sensitivity. In these cases, the amblyopia index was calculated using the average contrast sensitivity functions of normal monkeys and the amblyopic eye of experimental monkeys. Upon completion of behavioral testing at $\sim 4$ years of age, the microelectrode recording experiments were conducted in V2.

Recording and stimulation. The surgical preparation and the recording and stimulation methods were described previously in detail (Maruko et al., 2008; Tao et al., 2012, 2014; Zhang et al., 2013). Briefly, monkeys were anesthetized initially with an intramuscular injection of ketamine hydrochloride $(15-20 \mathrm{mg} / \mathrm{kg})$ and acepromazine maleate $(0.15-0.2 \mathrm{mg} / \mathrm{kg})$. The animals were paralyzed by an intravenous infusion of vecuronium bromide (a loading dose of $0.1-0.2 \mathrm{mg} / \mathrm{kg}$ followed by a continuous infusion of $0.1-0.2 \mathrm{mg} / \mathrm{kg} / \mathrm{h}$ ) and artificially respired with a mixture of $59 \% \mathrm{~N}_{2} \mathrm{O}, 39 \% \mathrm{O}_{2}$, and $2 \% \mathrm{CO}_{2}$. Anesthesia was maintained by the continuous infusion of a mixture of sufentanyl citrate $(0.05 \mu \mathrm{g} / \mathrm{kg} / \mathrm{h})$ and propofol $(4 \mathrm{mg} / \mathrm{kg} / \mathrm{h})$. The core body temperature was kept at $37.6^{\circ} \mathrm{C}$. Cycloplegia was produced by $1 \%$ atropine sulfate and the animals' corneas were protected with rigid, gas-permeable, extended-wear contact lenses. Retinoscopy was used to determine the contact lens parameters required to focus the eyes on the stimulus screen.

Electrode penetrations were confined to a parasagittal plane and the angle of the penetration was typically $15^{\circ}$ from vertical. The penetrations were started right behind the blood vessels running along the lunate sulcus and 15-17 mm lateral to the midline. The penetrations ended when the electrode exited V2. For each penetration, the cortical depth for each isolated unit was recorded. This approach allowed us to sample units consistently from similar regions of V2 in all subjects. Nearly all receptive fields were located within $5^{\circ}$ of the center of the projected fovea.

A monitor (Vision Research Graphics) with ultrashort persistence (frame rate $=140 \mathrm{~Hz}, 800 \times 600$ pixels) was used to present visual stimuli. The viewing distance was set to $114 \mathrm{~cm}$, where the display subtended a visual angle of $20^{\circ}$ (horizontal) $\times 15^{\circ}$ (vertical). Multiunit or single-unit activities were extracellularly recorded with tungsten-in-glass microelectrodes (Fredric-Haer). Action potentials from individual cortical neurons were amplified, digitized at $25 \mathrm{kHz}$, and stored using the data acquisition components in our workstation (Tucker-Davis Technology, System 3). During recording experiments, the spike-sorting software in our data acquisition system (System 3 ) was used to maintain the quality of isolation and to ensure that we were recording from the same units throughout each run. After the completion of the entire experiment for a given animal, custom-made spike-sorting software was used offline to isolate spiking activity from up to three nearby units for subsequent data analyses.

Experiments and data analysis. Neurons' responses to drifting sinewave gratings were sampled at a rate of $140 \mathrm{~Hz}$ (7.14 ms bin widths) and compiled into peristimulus time histograms (PSTHs) that were equal in duration to, and synchronized with, the temporal cycle of the grating. The amplitude and the phase of the temporal response components in the PSTHs were determined by Fourier analysis. For each neuron, the orientation, spatial frequency, and size-tuning functions were first obtained using sine wave gratings $(80 \%$ contrast and temporal frequency $=$ $3.1 \mathrm{~Hz}$ ). The preferred orientation, spatial frequency, and size for each receptive field were determined using the methods described previously in detail (Tao et al., 2012, 2014). For the noise measurements, the optimized stimuli for each neuron were presented to the right or left eyes in a randomly ordered sequence for relatively short periods (640 ms). Rerandomized stimulus sequences were repeated 25 times during a given experiment. Blank stimuli (i.e., zero contrast control) were included in each repeat to provide a measure of the neuron's maintained firing rate. Because the nature of perceptual impairments in amblyopes depends on stimulus contrast, we repeated the measurements for the following stimulus contrasts: $0.0 \%, 1.0 \%, 2.5 \%, 5.0 \%, 10 \%, 25 \%$, $50 \%$, and $80 \%$ (see Fig. $1 B$ )

Spiking dynamics. Figure $1 A$ illustrates how response timing was quantified before, during, and after $640 \mathrm{~ms}$ stimulations. The following were measured: (1) the baseline firing (base), (2) the onset latency, (3) the time to reach one half of the peak firing (time to half peak), (4) the time to peak, and (5) the decay in firing, defined as the ratio between the responses at peak and "platform" and calculated as decay $=$ (peak platform $) /($ peak + platform $-2 *$ base). The onset latency was determined by measuring the time between stimulus onset and the time at which the neuron's response significantly exceeded the background noise distribution: specifically, over 3 consecutive $1 \mathrm{~ms}$ bins, exceeding a Poisson distribution of spontaneous spiking measured for a period of 100 ms preceding the stimulus onset and at a level corresponding to a probability of $p=0.01$ (Maunsell et al., 1992). 
For better resolution, spike count data were presented as impulse density functions produced by smoothing the $1 \mathrm{~ms}$ PSTHs with a discretetime Gaussian pulse with a SD of $3 \mathrm{~ms}$. The spiking histograms represent the spike counts for all cells in each group (normal, fellow, and amblyopic) and all 25 repeats. The same number of cells from each cell group were randomly resampled and their latency, time-to-half-peak, and time-to-peak were calculated 2000 times. The median estimated timing and their confidence intervals were calculated from these 2000 repeats. A bootstrap method was used to test for significant differences between cell groups. This was performed by mixing random cells from a pair of the three cell groups as the total number of neurons for the smaller group and the timings for the new sampling population were calculated. This procedure was performed 20,000 times and the results sorted. The original timing ranked $0.5 \%$ or $99.5 \%$ of the repeat pool and was identified as significantly different from the other group.

Noise in spiking. Spiking noise was quantified by calculating the $\mathrm{CV}^{2}$ and FF. The $\mathrm{CV}^{2}$ of operational ISIs quantifies spike train irregularities within trials. Operational spike timing was obtained by using the cumulative smoothed peristimulation histogram $(\lambda)$ for each cell at original timing as follows: $t^{\prime}=\int_{0}^{t} \lambda(s) d_{s}$. The operational ISIs represents the intervals between their operational timing $\left(\Delta t^{\prime}\right)$. ISIs were sequenced for all trials within a $640 \mathrm{~ms}$ stimulation window. The variance and mean of the operational ISI sequence were then calculated to obtain $C V^{2}=\operatorname{Var}\left(\Delta t^{\prime}\right) / E\left(\Delta t^{\prime}\right)^{2}$ for each cell (Nawrot et al., 2008). Bonferroni corrected $t$ tests were performed to check for significant differences between the cell groups.

The FF of spike count reveals spiking irregularity between trials (trialto-trial fluctuations) and m-FFs were calculated (Churchland et al., 2010). The m-FFs were processed from the histograms of mean spike counts for all cells within a time window of interest for each cell group. At each spike-count bin, the same number of cells as the smallest group was subsampled. Combining cells from all bins, FF was calculated as the least-square solution for $\operatorname{Var}_{i}=F F \times E_{i}$. The average FFs and average estimated SEs of 50 resamplings were defined as $\mathrm{m}-\mathrm{FF}$ and its MSE. The $p$-values between $\mathrm{m}$-FF groups were computed as the normal cumulative distribution function of $\sigma=\sqrt{M S E_{1}^{2}+M S E_{2}^{2}}$ at $-\left|\mathrm{m}-\mathrm{FF}_{1}-\mathrm{m}-\mathrm{FF}_{2}\right|$. All $p$-values were determined by applying Bonferroni correction.

Sliding windows of 50 and $200 \mathrm{~ms}$ at $10 \mathrm{~ms}$ steps were used to measure the spike counts and FFs to characterize the dynamics of spiking rate and spiking noise before, during, and after stimulation. Because the shorter sampling window includes fewer spikes compared with the full $640 \mathrm{~ms}$ stimulation period, in some cases and there were no spikes across all trials within our 25 repeats, those cells and time bins would not have valid $\mathrm{CV}^{2}$ and FF values. As an impact for the group total, both $\mathrm{CV}^{2}$ and FF would be underestimated compared with real values, so the data from those cells were not included in the analysis.

Binocular interactions. Responses were collected for dichoptic sinewave gratings of the optimal spatial frequency, orientation, and direction of drift as a function of the relative interocular spatial phase disparity of the grating pair (Ohzawa and Freeman, 1986a,1986b; Chino et al., 1997; Smith et al., 1997; Bi et al., 2011). To characterize whether binocular signal interactions were facilitatory or suppressive in nature, the "peak binocular response amplitude/dominant monocular response amplitude" ratios (peak $B / M$ ) were calculated for each neuron and expressed in terms of relative strength $(\mathrm{db})$, that is, $10 \log$ peak B/M (Maruko et al., 2008; Bi et al., 2011). Negative peak B/M values signify binocular suppression and positive values indicate binocular facilitation.

Statistics. Unless specified otherwise, multiple pairwise comparisons were made using $t$ tests with Bonferroni corrections for the three cell groups ("normal," "amblyopic," and "fellow" will be used to describe the results).

\section{Results}

We recorded from 748 V2 neurons in the five amblyopic and 224 V2 neurons in three normal monkeys. For the amblyopic monkeys, the quantitative analysis of responses was performed in 655 neurons via stimulations of the amblyopic eye and 394 units via the fellow eye. For the normal monkeys, we analyzed the re-

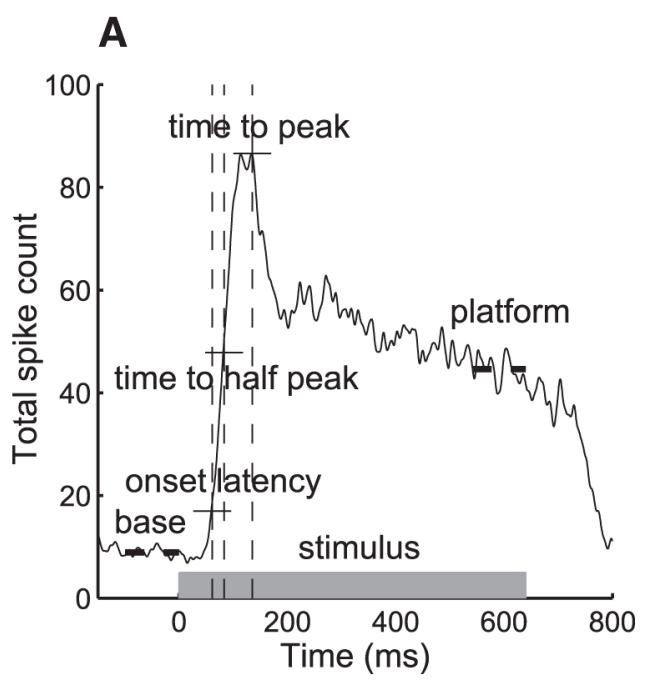

B

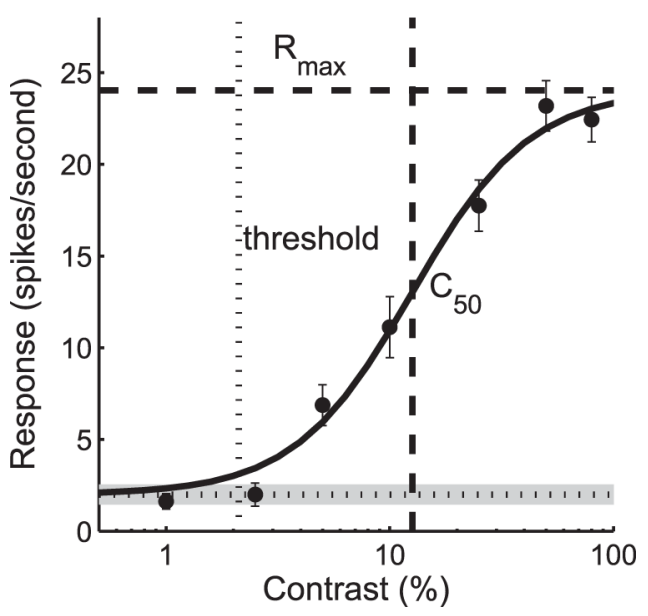

Figure 1. Methods to measure response dynamics and contrast sensitivity. $\boldsymbol{A}$, Population onset latency, time to "half-peak," time to peak (vertical dash lines), and spontaneous "base" response and "platform" (thick horizontal dash lines). Gray thick bar indicates stimulation duration. Horizontal thin lines indicate thresholds for each timing measure. $\boldsymbol{B}$, Contrast versus response function of an example cell. Horizontal dotted line indicates spontaneous response, and gray shading shows confidence interval. Vertical thin dotted line shows contrast threshold. Horizontal dash line indicates estimated $R_{\max }$. Vertical thick dashed line shows $C_{50}$.

sponses of stimulations of the dominant eye. To analyze the dynamics of spike counts and spiking noise, we presented brief $(640$ ms) drifting $(T F=3.1 \mathrm{~Hz})$ sine wave gratings optimized for orientation, spatial frequency, and size for each neuron (Fig. 1A). Stimulus contrast was varied from $0 \%$ to $80 \%$ (Fig. $1 B$ ).

\section{Dynamics of spike counts}

The spiking dynamics of amblyopic V2 neurons, driven either by the amblyopic (amblyopic) or fellow eye (fellow), were substantially different from that for normal neurons (normal) and the differences were contrast dependent (Fig. 2). For example, spontaneous discharge ( $0 \%$ contrast) was significantly higher for neurons in amblyopic monkeys (both fellow and amblyopic) than for normal neurons ( $p<0.001$; cf. Fig. $2 A-C$ ). For higher stimulus contrasts ( $50 \%$ and $80 \%)$, the onset latency and the time to reach the $1 / 2$ of the peak response amplitude were significantly shorter for amblyopic neurons than comparable values in normal monkeys. However, the time to reach the response peak was quite variable in amblyopic neurons. In addition, unlike the relatively 


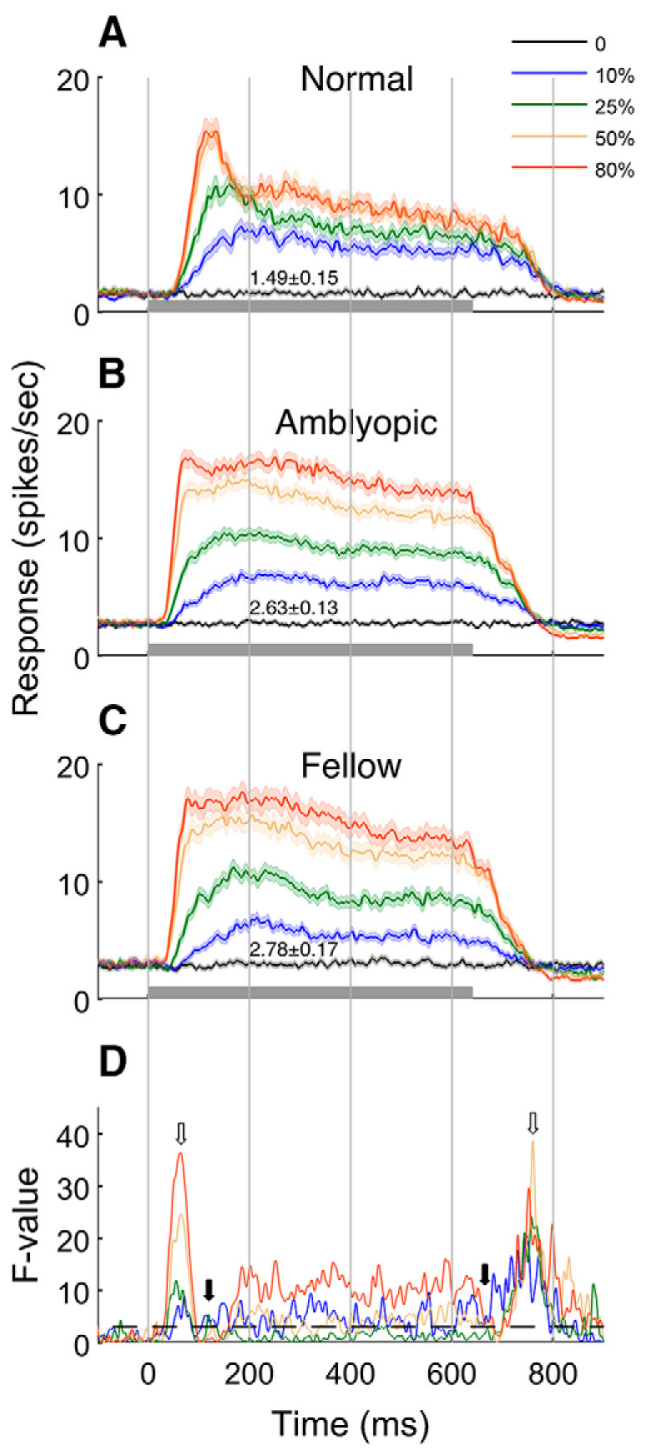

Figure 2. Dynamics of spike count (mean $\pm \mathrm{SE}$ ) for a range of stimulus contrasts $(\boldsymbol{A}-\boldsymbol{C})$ and F-value of ANOVA test (D). Dashed line represents $p=0.05$ threshold. $\boldsymbol{A}$, Mean responses of normal cells. $\boldsymbol{B}$, Mean response of amblyopic eye stimulation. $\boldsymbol{C}$, Mean response of fellow eye stimulations. Open arrows indicate the time with the highest $F$-value and filled arrows indicate the time with the lowest $F$-value.

rapid decline of response rates after the peak in normal neurons, the response decay after the peak was much slower or absent at all contrasts in amblyopic monkeys (both via fellow and amblyopic stimulation). This resulted in the apparent lack of the onset transient responses (Fig. $2 B, C$ ) that are common in normal neurons for moderate and high contrasts (Fig. 2A). The responses of amblyopic neurons were sustained and relatively constant until the stimulus was turned off. Unlike normal neurons, in which spiking continued for about $100 \mathrm{~ms}$ after stimulus was turned off, there was an immediate sharp decay in the responses of neurons in amblyopic monkeys. Note that there was a small but notable inhibition of spontaneous firing after high-contrast stimuli (Fig. $2 B, C)$. These temporal changes in spike counts are reflected in differences at a given time from stimulus onset between the cell groups (running F-values; Fig. 2D). The larger differences between the normal and amblyopic neurons were located at the rising (on) and the falling (off) segments (small open arrows), whereas minimal differences occurred around the peak response and at stimulus offset (small filled arrows).
The cell population data show that the onset latency of neurons driven by the amblyopic or fellow eye was consistently shorter by about $20 \mathrm{~ms}$ than that in normal neurons at the $50 \%$ and $80 \%$ contrasts $(p<0.001$; Fig. $3 A$ ). Similar differences were found for the times to the half peak, although the differences were $\sim 30-40 \mathrm{~ms}(p<0.001)$. The average time to reach the peak response tended to be longer for neurons in amblyopic monkeys (both fellow and amblyopic). However, these differences were not statistically significant at any stimulus contrast because of the large interneuronal variation for the time to the peak response (Figs. $2 A-C, 3 C$ ). Importantly, the response decays after the peak, measured by the peak/platform amplitude ratios (Fig. $1 A$ ), were consistently lower (i.e., slower decay) in amblyopic and fellow eye neurons at all contrasts except for $10 \%(p<0.001$; Fig. $3 D)$. Overall, the spiking dynamics of amblyopic neurons were substantially different from that for normal neurons.

Finally, because of the stronger sustained responses, the mean firing rate of amblyopic neurons (driven by both the amblyopic and fellow eyes) was significantly higher than that for normal neurons at the $50 \%$ and $80 \%$ contrasts $(p<0.001$; Fig. $3 E)$. The spike rate at $25 \%$ was also significantly higher for neurons driven by the amblyopic eye $(p<0.005)$ but not by the fellow eye. As mentioned above, the spontaneous firing of amblyopic neurons $(0 \%$ contrast $)$ was also significantly higher than that in normal neurons $(p<0.001)$. Note that, in contrast to normal neurons, in which response saturation occurred at $\sim 50 \%$ contrast, the average response of amblyopic neurons did not appear to saturate even for the highest stimulus contrast (80\%). These results on the overall responsiveness of $\mathrm{V} 2$ neurons in monkeys with moderate amblyopia are in sharp contrast to the "impoverished" responses of V1 neurons that have been typically cited for severely amblyopic animals (for reviews, see Kiorpes, 2006; Levi, 2013).

\section{Contrast versus response}

To better understand these contrast-dependent anomalies, we fit the contrast versus response data for each neuron with a hyperbolic function and calculated the contrast threshold, the overall contrast sensitivity $\left(C_{50}\right)$, the contrast gain (the slope of the contrast response function, $(n)$, and the saturated response or maximum attainable response $\left(R_{\max }\right)$. Not surprisingly, the median contrast threshold of amblyopic neurons (fellow or amblyopic eyes) was significantly higher than that of normal neurons (Fig. $4 A$; Kruskal-Wallis test, $p<0.001)$. Similarly, the overall contrast sensitivity was lower $\left(C_{50}\right.$ was higher $)$ for amblyopic neurons (Fig. 4B; Kruskal-Wallis test, $p<0.001$ ). As predicted from the data shown in Figure $3 E$, a substantial number of amblyopic V2 neurons did not show contrast saturation $<100 \%$ (Fig. $4 C$ ), so their median $R_{\max }$ and $C_{50}$ values for amblyopic neurons were significantly higher than that for normal neurons (Kruskal-Wallis test, $p<0.001)$. Finally, the contrast gains $(n)$ were similar but slightly lower for amblyopic neurons compared with those for the fellow or normal neurons (Fig. 4D; Kruskal-Wallis test, $p<$ $0.01)$. Together, these data on contrast versus response suggest that the contrast normalization mechanisms of many amblyopic neurons may not be functioning normally.

The abnormal response dynamics and the abnormal contrast normalization of amblyopic neurons described thus far reflect developmental alterations in the underlying connectivity of V2 in amblyopic monkeys and are predictive of enhanced spiking noise that could interfere with information processing. 
A

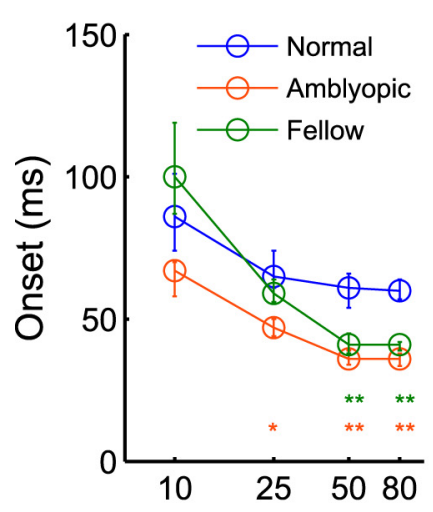

D

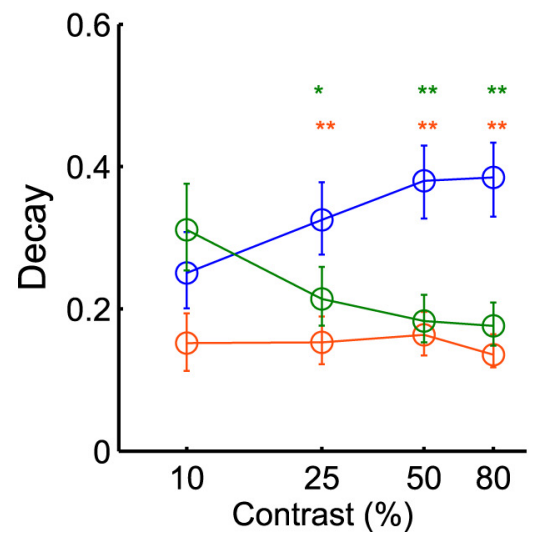

B

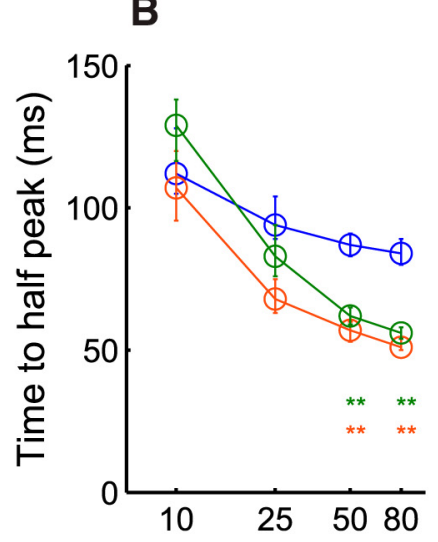

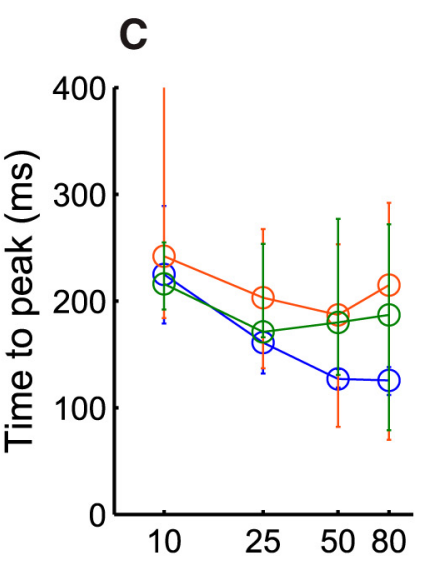

E

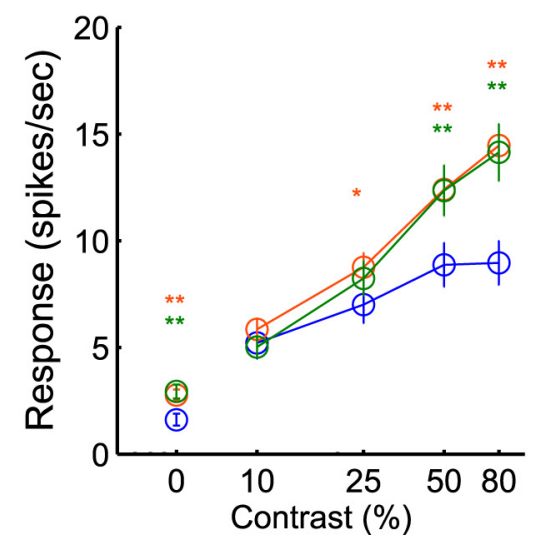

Figure 3. Population analysis on onset latency $(\boldsymbol{A})$, time to half-peak $(\boldsymbol{B})$, time to peak $(\boldsymbol{C})$, decay $(\boldsymbol{D})$, and mean spike count $(\boldsymbol{E})$. Error bars indicate confidence intervals. ${ }^{* *} p<0.001$, ${ }^{*} p<0.01$.

$\mathrm{CV}^{2}$

Spiking noise arises from irregularities in the spike train and from trial-to-trial variability (Nawrot et al., 2008; Churchland et al., 2010). Here we first analyzed the spiking irregularity by calculating the square of the coefficient of variation of the ISIs $\left(\mathrm{CV}^{2}\right)$ within the $640 \mathrm{~ms}$ stimulus window. Specifically, we calculated the "operational time" $\mathrm{CV}^{2}$, which controls for the effects of dynamic changes in the neuronal firing rate that may result in an overestimation of $\mathrm{CV}^{2}$; that is, "demodulation" (Nawrot et al., 2008).

The $\mathrm{CV}^{2}$ was elevated in amblyopic neurons driven by either the amblyopic or the fellow eye (Fig. 5). The degree of spike train irregularity for amblyopic neurons was contrast dependent; the difference in noise $\left(\mathrm{CV}^{2}\right)$ between the amblyopic and normal neurons was largest for the highest contrast (80\%) and smallest at the lowest contrast (10\%; Fig. 5A). However, only the difference for the $80 \%$ contrast reached statistical significance $(p<0.001)$. The observed increase in spike train irregularity $\left(\mathrm{CV}^{2}=\right.$ variance/squared mean of ISI) at the $80 \%$ contrast was largely due to the abnormally high variance in the operational ISI in amblyopic neurons relative to that for normal neurons ( $p<0.001$; Fig. $5 B$ ) rather than an abnormally reduced squared mean of ISI (Fig. $5 C$ ). It is worth noting that the variance of the ISI for normal neurons at $80 \%$ was lower than that at $50 \%$, whereas the variance at $80 \%$ for amblyopic neurons was higher than that for $50 \%$ contrast. However, the contrast-dependent differences in the squared mean of the ISI between normal and amblyopic neurons were minimal (Fig. 5C). For $80 \%$ contrast stimuli, the correlation be- tween the $\mathrm{CV}^{2}$ and the spike count in individual neurons was very high $(r=0.87, p<0.001)$ for normal neurons, whereas the relationship was much weaker for amblyopic neurons $(r=0.33$ for amblyopic and $r=0.35$ for fellow, $p<0.001$; Fig. 5D).

Because the elevated $\mathrm{CV}^{2}$ of amblyopic neurons did not simply result from their higher spike counts, we compared the $\mathrm{CV}^{2}$ at $80 \%$ contrast of each neuron with its $R_{\max }$ value (Fig. $5 E$ ). These two values were well correlated with each other in normal neurons $(r=0.84, p<0.001)$. In contrast, the correlations were weaker in both amblyopic and fellow neurons $(r=0.27$ and $r=$ $0.25, p<0.001$ ), suggesting that subnormal contrast adaptation mechanisms contributed to the anomalous spiking noise at high contrast. For this analysis, it is important to keep in mind that those neurons in which $R_{\max }$ exceeded 100 were excluded from the analysis and that many more amblyopic neurons had $R_{\max }$ values that were far higher than 100 .

The spontaneous firing was significantly higher (Fig. 3E) and more variable in amblyopic neurons; the spike train irregularity $\left(\mathrm{CV}^{2}\right)$ during spontaneous firing (contrast $\left.=0 \%\right)$ was significantly greater for amblyopic neurons (both fellow and amblyopic) than that in normal neurons ( $p<0.001$; Fig. 5A). Importantly, the spiking count irregularity $\left(\mathrm{CV}^{2}\right)$ during the spontaneous firing of an amblyopic neuron can reasonably predict the neuron's $\mathrm{CV}^{2}$ in the response to $80 \%$ contrast stimulus $(r=0.67, p<0.001$ for the amblyopic eye and $r=0.47, p<0.001$ for the fellow eye; Fig. $5 F)$. This relationship was weaker in normal neurons $(r=0.24, p<0.001)$. Therefore, at least for amblyo- 

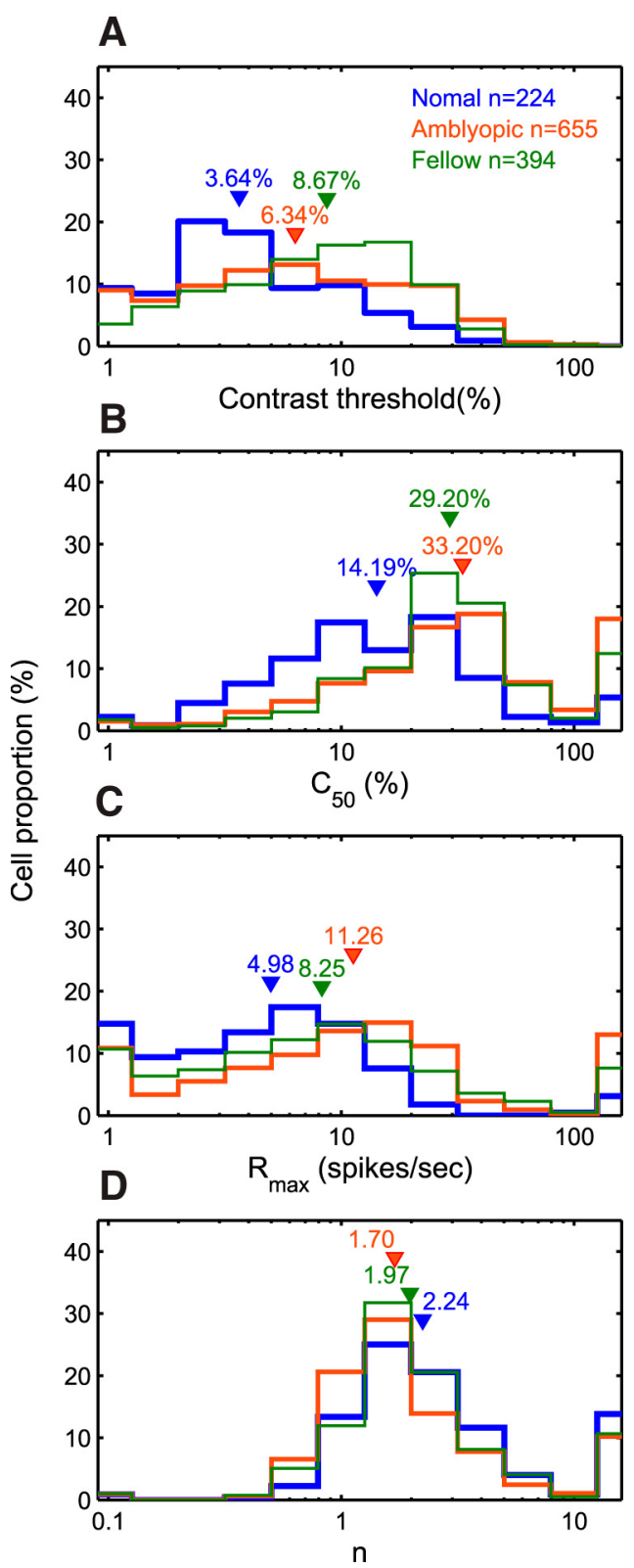

Figure 4. Distributions of contrast-gain properties. $\boldsymbol{A}$, Contrast threshold. $\boldsymbol{B}, \boldsymbol{C}_{50} . \boldsymbol{C}, R_{\max }$. $D$, Gain index $n$. Downward triangles indicate median values of each cell group.

pic neurons, the spiking noise during spontaneous discharge contributes more to the spiking noise during visual stimulation.

\section{Trial-to-trial variability (FF)}

Excessive trial-to-trial fluctuations in spiking could also contribute to "random" or "internal" noise in the amblyopic visual system. Here, we compared the variance-to-mean ratios (FF) of amblyopic and normal V2 neurons using a rate-matching approach (Churchland et al., 2010). Stimuli were the same as above $(640 \mathrm{~ms}$ in duration and repeated 25 times with a rest period of $320 \mathrm{~ms}$ ).

In contrast to $\mathrm{CV}^{2}$, the $\mathrm{m}-\mathrm{FF}$ in amblyopic neurons (both fellow and amblyopic) was significantly higher compared with normal neurons only for low contrasts (10\% and 25\%; Fig. 6). Temporal changes in $\mathrm{m}-\mathrm{FF}$ were quantified using spike counts computed in a $200 \mathrm{~ms}$ sliding window moving in $10 \mathrm{~ms}$ steps (Fig. $6 A-D)$. Data are aligned on stimulus onset. Except for the $10 \%$ stimulus contrast, the m-FF dropped drastically during the first $200 \mathrm{~ms}$ (during the transient onset responses) in all cell groups. This observation in V2 is similar to a sharp drop of m-FF around stimulus onset for normal neurons in eight other primate visual areas (Churchland et al., 2010). Note that the m-FF in normal monkeys stayed low throughout the stimulation period and there was no apparent differences in the m-FF between any cell group for the higher contrast stimuli (50\% and 80\%; Fig. 6C,D). However, at $25 \%$ contrast, substantial differences became apparent between amblyopic (both fellow and amblyopic eyes) and normal neurons after a sharp drop at stimulus onset; that is, beginning around $300 \mathrm{~ms}$ (Fig. 6B). At 10\% stimulus contrast, the drop of $\mathrm{m}$-FF at stimulus onset was minimal, but the m-FF was generally higher for amblyopic neurons than that for normal neurons (Fig. $6 A$ ). The difference between normal and amblyopic neurons also emerged earlier (around $100 \mathrm{~ms}$ ) for 10\% stimuli.

The cell population data show that, for $50 \%$ and $80 \%$ stimulus contrasts, the m-FF for amblyopic neurons was similar to that in normal neurons (Fig. $6 E$ ). These $\mathrm{m}$-FF values in normal V2 are generally similar to those for other early-to-middle extrastriate visual areas (Churchland et al., 2010). However, for the gratings with lower stimulus contrasts $(10 \%$ and $25 \%)$, the m-FF was significantly higher for the fellow and amblyopic eye stimulation $(p<0.001)$. The high m-FF of amblyopic neurons resulted largely from abnormally elevated variance in spike counts at these low contrasts (Fig. 6F,G). Therefore, the trial-to-trial fluctuations in spiking were present in amblyopic neurons only during "weaker" responses initiated by low-contrast stimuli.

Another important result was that the m-FF during spontaneous activity in amblyopic neurons was correlated with the m-FF during stimulations with $25 \%$ contrast stimuli (Fig. $6 \mathrm{H}$ ). Although a similar correlation was found for normal neurons $(r=$ $0.42, p<0.001)$, the correlation for amblyopic neurons was a bit stronger for amblyopic $(r=0.56, p<0.001)$ and fellow eye stimulation $(r=0.63, p<0.001)$.

In normal animals, the spike count irregularity $\left(\mathrm{CV}^{2}\right)$ and the trial-to-trial variability $(\mathrm{FF})$ are closely related to each other: $\mathrm{FF} /$ $\mathrm{CV}^{2}=1.0$ (Nawrot et al., 2008). For normal V2 neurons, the operational $\mathrm{CV}^{2}$ values of individual neurons were generally similar to their spike count m-FF regardless of stimulus contrast, so the slope of the function relating the 2 values was near 1.0 (Fig. $7 A-D)$. For lower contrast stimuli (10\% and $25 \%)$, the $\mathrm{CV}^{2}$ values of individual neurons were also similar to their FF for all cell groups (Fig. $7 A, B)$. However, for higher contrast gratings (50\% and $80 \%$ ), more amblyopic neurons exhibited relatively larger spike train variability $\left(\mathrm{CV}^{2}\right)$ compared with their trial-to-trial variability (m-FF), deviating from the ratio of 1.0 (Fig. $7 C, D$ ).

The temporal changes in the ratio between the spike count FF and $\mathrm{CV}^{2}$ before, during, and after the $640 \mathrm{~ms}$ stimulation period revealed additional information about the relationship between $\mathrm{FF}$ and $\mathrm{CV}^{2}$ (Fig. $7 E-H$ ). For normal neurons, the $\mathrm{FF} / \mathrm{CV}^{2}$ ratio was $\sim 1.0$ before, during, and after the stimulation for all contrasts, although there was a slight tendency toward a higher ratio near the end of stimulation. For lower contrasts (10\% and 25\%), there was no difference between normal and amblyopic neurons (Fig. $8 E, F$ ). For $50 \%$ contrast, the ratio for amblyopic neurons was lower than 1.0 during stimulation, especially for the fellow eye (Fig. 7G). At $80 \%$ stimulus contrast, the ratio for amblyopic neurons (both the fellow and amblyopic eyes) substantially decreased from 1.0 during the onset transient response ( $\sim 200 \mathrm{~ms}$ ) and gradually recovered until the offset of the stimulus at $640 \mathrm{~ms}$ (Fig. $7 H$ ). Therefore, if amblyopic neurons are driven strongly, 

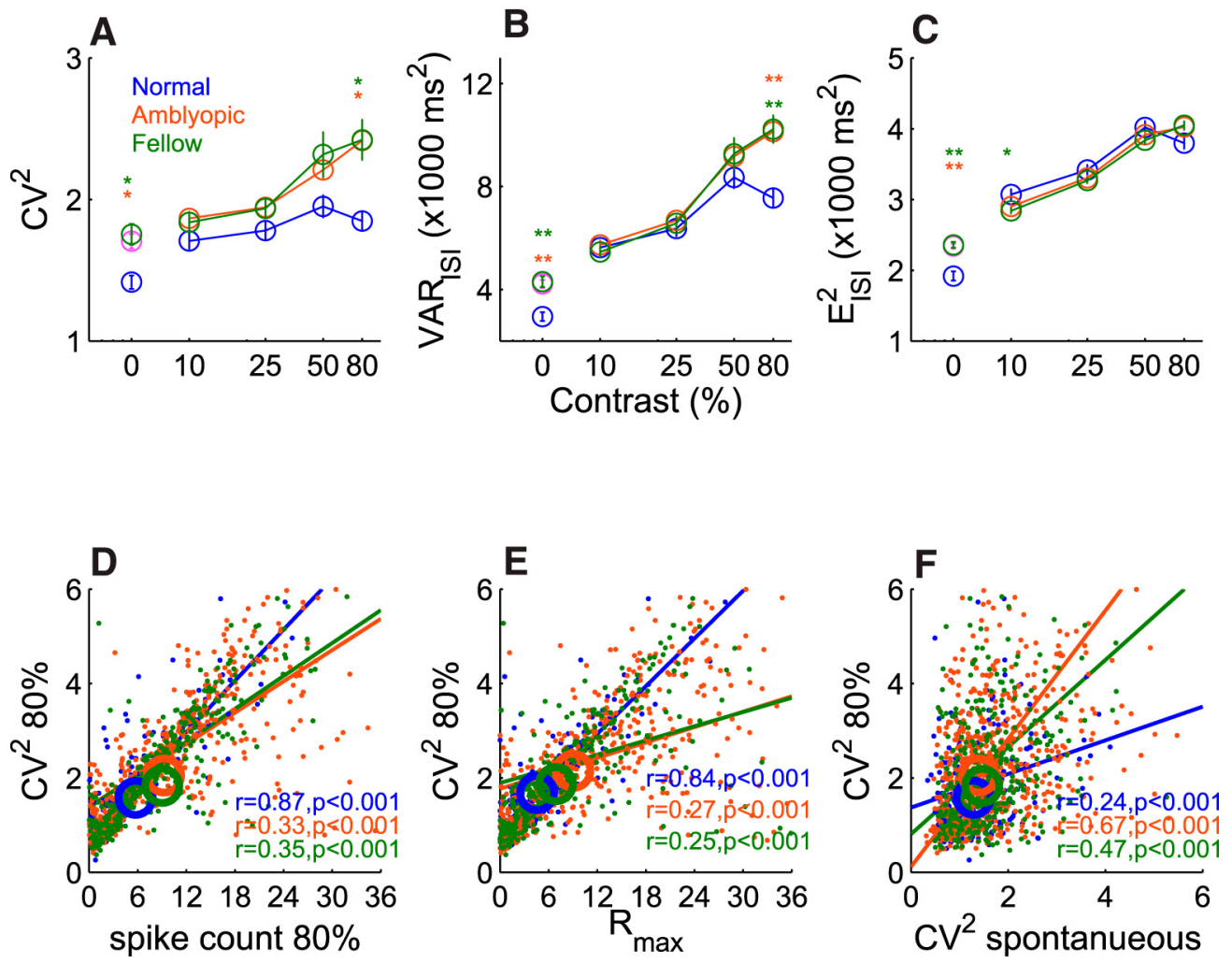

Figure 5. Population analysis on operational $\mathrm{CV}^{2}$. A, Operational $\mathrm{CV}^{2}$. B, Variance of operational ISI. C, Squared mean of operational ISI. D, Operational CV ${ }^{2}$ versus spike count for $80 \%$ contrast. $E, C V^{2}$ at $80 \%$ contrast versus $R_{\text {max }} . F, C V^{2}$ at $80 \%$ contrast versus spontaneous $C V^{2}$. Center coordinates of circles indicate medians of each cell groups. Error bars indicate $S E$. ${ }^{* *} p<0.001,{ }^{*} p<0.01$.

the noise due to spike count variability $\left(\mathrm{CV}^{2}\right)$ dominates the $\mathrm{FF} / \mathrm{CV}^{2}$ ratio (i.e., $\mathrm{FF} / \mathrm{CV}^{2}$ ratio $\ll 1.0$ ).

\section{Binocular suppression}

To search for a potential source of the observed high spiking noise in amblyopic V2, we looked into the level of binocular suppression that is known to be highly prevalent in amblyopic primates (Smith et al., 1997; Bi et al., 2011; Tao et al., 2014). To determine whether binocular signal interactions were facilitatory or suppressive in nature, the peak binocular response amplitude/ dominant monocular response amplitude ratios (B/M) were calculated for each neuron and expressed in terms of relative strength ( $\mathrm{db}$ ); that is, 10 log peak binocular/monocular. We compared the mean $\mathrm{B} / \mathrm{M}$ values and the prevalence of binocularly suppressive neurons for individual monkeys (Fig. 8). Each neuron was classified as a binocularly suppressive neuron if the neuron's responses to dichoptic stimulation were less than the dominant monocular responses $(10 \log$ peak $\mathrm{B} / \mathrm{M}$ in $\mathrm{db}<0.00)$. Neurons in our amblyopic monkeys generally showed much lower mean $\mathrm{B} / \mathrm{M}$ ratios and a higher prevalence of binocularly suppressive neurons than the comparable values for normal neurons. Next, we examined the possibility that binocular suppression or loss of binocular facilitation may be related to the enhanced spiking irregularity of amblyopic V2 neurons. The mean $\mathrm{CV}^{2}$ for individual monkeys measured with $80 \%$ contrast were negatively correlated with the mean $\mathrm{B} / \mathrm{M}$ ratios $(r=-0.85$, $p<0.03$; Fig. $8 D$ ) and positively correlated with the prevalence of binocularly suppressive neurons $(r=0.98, p<0.01$; Fig. $8 H)$. For lower stimulus contrasts, these types of correlations were progressively weaker and not significant (Fig. $8 A-C, E-G$ ). The contrast-dependent correlations between spiking irregularities and binocular suppression were not surprising because the mean
$\mathrm{CV}^{2}$ of amblyopic neurons were significantly higher than that in normal monkeys only for $80 \%$ stimulus contrast (cf. Figs. $5 A$, $8 A-H)$. This association suggests that there may be a link between binocular suppression and $\mathrm{CV}^{2}$ in V2 of amblyopic monkeys that should be explored further.

As with $\mathrm{CV}^{2}$, we determined whether there is any association between the level of binocular suppression and the m-FF of amblyopic V2 neurons in individual monkeys (Fig. 8I-P). At 10\% contrast, there was a significant positive correlation between the prevalence of binocularly suppressive neurons and the mean $\mathrm{m}$-FFs of individual monkeys $(r=0.84, p=0.04$; Fig. $8 M)$. The negative correlation between the mean $\mathrm{m}-\mathrm{FF}$ and the mean $\mathrm{B} / \mathrm{M}$ ratios for individual monkeys was relatively strong, but did not reach statistical significance $(r=-0.55, p=0.26$; Fig. $8 I)$. At higher contrasts, the correlations became progressively weaker and not significant with stimulus contrast. These data parallel the average $\mathrm{m}$-FF for the three cell groups (Fig. 6E) and suggest that binocular suppression may be involved with abnormal $\mathrm{m}-\mathrm{FF}$ in V2 of amblyopic monkeys.

\section{Relation to behavioral data}

Our amblyopic monkeys exhibited a broad range of contrast sensitivity loss. Therefore, we investigated whether the contrast versus response functions and the level of spiking noise $\left(\mathrm{CV}^{2}\right.$ and $\mathrm{m}-\mathrm{FF}$ ) in V2 neurons of individual monkeys had any relationship to the severity of their perceptual loss.

\section{Contrast}

The average contrast threshold and $C_{50}$ of V2 neurons for individual monkeys were generally correlated with their amblyopia index (the degree of perceptual contrast sensitivity loss). Although the correlation between the contrast threshold of V2 neu- 

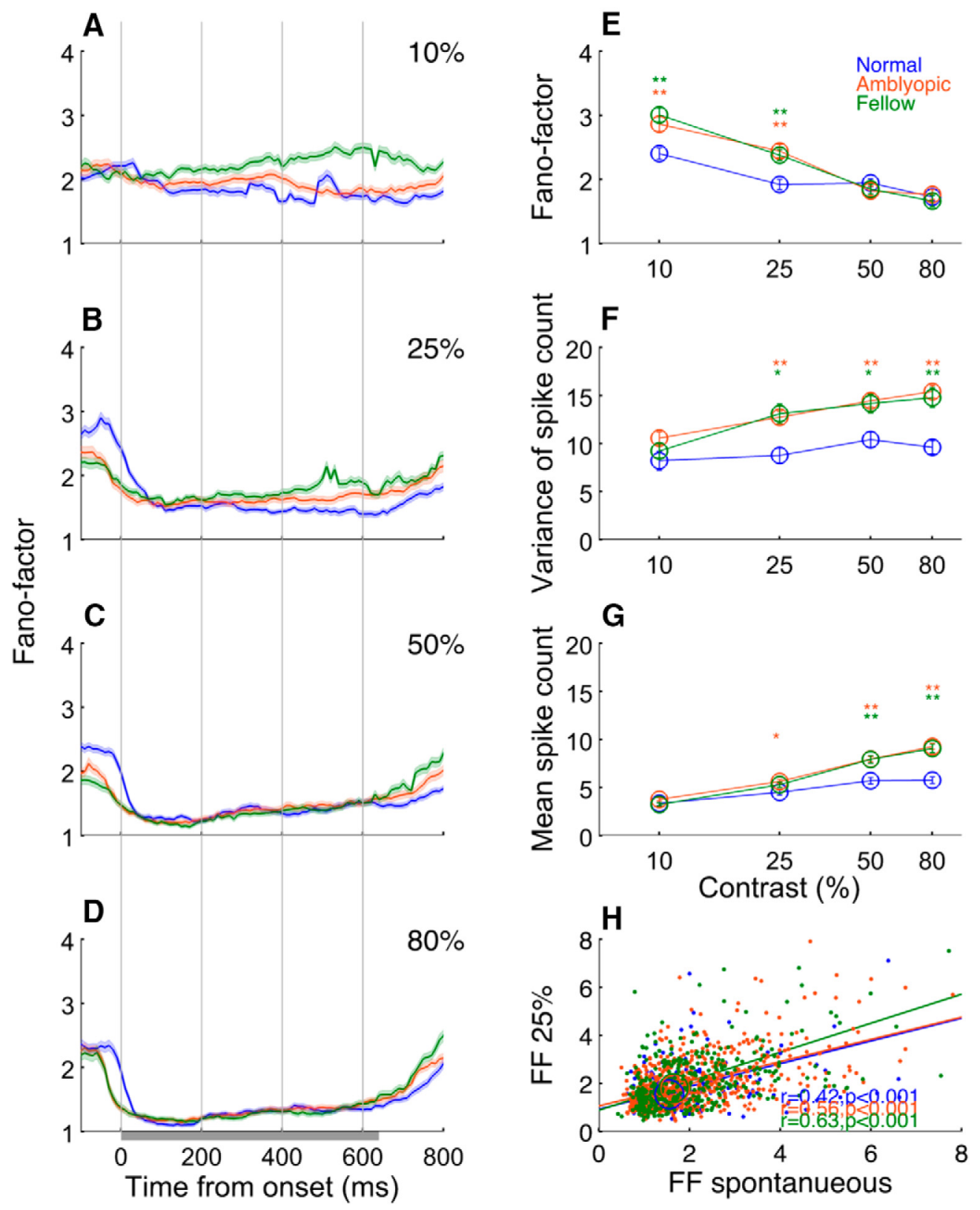

Figure 6. Contrast-dependent changes of FFs. $\boldsymbol{A}-\boldsymbol{D}$, Temporal changes in FFs under different contrast stimulations. $\boldsymbol{E}$, Population average of FFs as a function of stimulus contrast, $\boldsymbol{F}, \boldsymbol{G}$, Variance of spike count $(\boldsymbol{F})$ and mean of spike count as a function of stimulus contrast $(\boldsymbol{G})$. $\boldsymbol{H}$, FFs at $25 \%$ contrast versus FFs for spontaneous activity. Error bars indicate $\mathrm{SE}$. ${ }^{* *} p<0.001$, ${ }^{*} p<0.01$. Centers of circles indicate medians of each cell group.

rons and the amblyopia index missed statistical significance $(r=$ 0.77, $p=0.075$; Fig. 9A), the correlation between $C_{50}$ and the amblyopia index was quite strong $(r=0.94, p<0.01$; Fig. $9 B)$. The correlation between amblyopia index and the average $R_{\max }$ or $n$ of individual monkeys was weaker and not statistically significant. This pattern of results is not surprising because the amblyopia index generally reflects the subject's overall contrast sensitivity (Kiorpes et al., 1998; Wensveen et al., 2006).

\section{Noise}

The abnormal spiking noise of $\mathrm{V} 2$ neurons $\left(\mathrm{CV}^{2}\right.$ and $\left.\mathrm{m}-\mathrm{FF}\right)$ of individual monkeys was also correlated with their perceptual deficits and this relationship was contrast dependent. For example, there was a positive correlation between the average $\mathrm{CV}^{2}$ and the amblyopia index of individual monkeys when the stimulus contrast was $80 \%(r=0.90, p=0.015$; Fig. $9 H)$. For $50 \%$ stimulus contrast, this correlation was relatively strong but did not reach statistical significance $(r=0.74, p=0.09$; Fig. $9 G)$. For lower contrasts, the correlations were much weaker and not statistically significant (Fig. 9E,F).

Similarly, the average m-FFs for individual monkeys were generally correlated with the severity of their contrast sensitivity losses for individual monkeys for low stimulus contrasts, but not for high contrasts (Fig. 9I-L). These correlation data are internally consistent because the abnormal $\mathrm{CV}^{2}$ of amblyopic V2 neurons was statistically significant only for the $80 \%$ stimulus contrasts (Fig. 5A), whereas the significantly enhanced m-FFs of amblyopic neurons were observed just for low-contrast stimuli (Fig. 6E). Although this sort of cross-animal comparison in a limited number of subjects may not be the most powerful approach, there was a surprisingly strong association between V2 
A

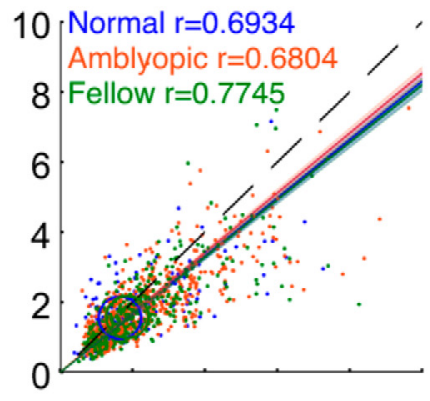

B
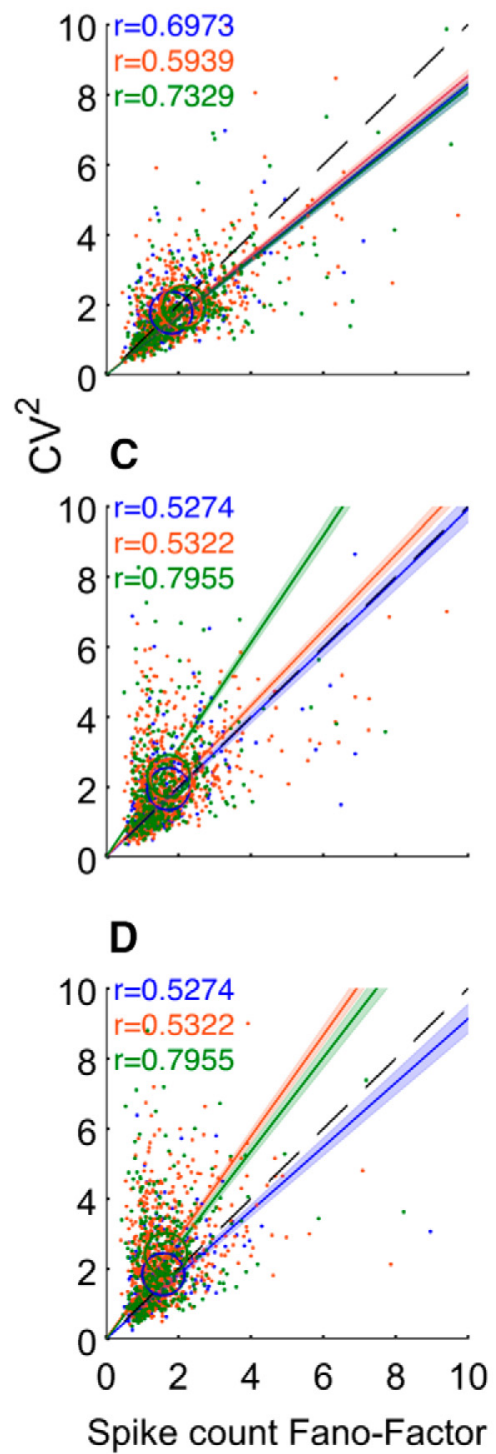

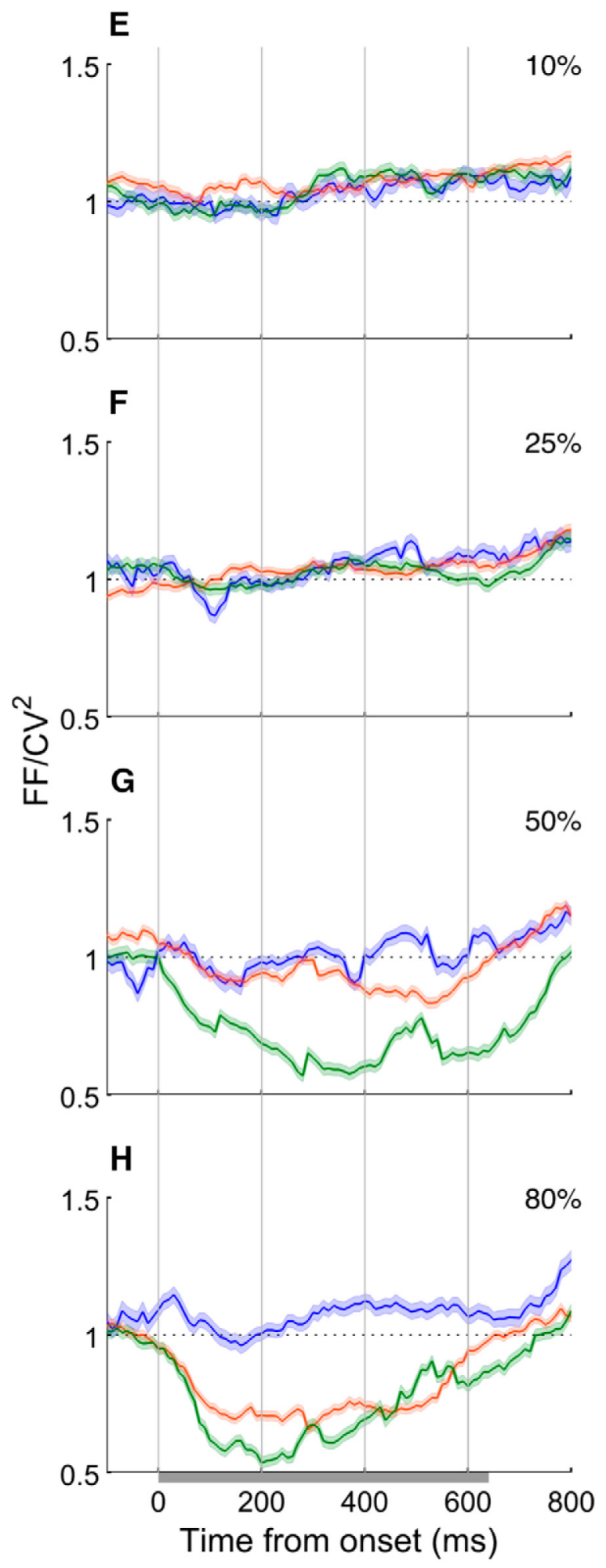

Figure 7. Correlations between $\mathrm{CV}^{2}$ and FF. $\boldsymbol{A}-\boldsymbol{D}, \mathrm{CV}^{2}$ versus FF at various contrasts. $\boldsymbol{E}-\boldsymbol{H}$ Dynamics of FF/CV ${ }^{2}$ ratios for different contrasts.

neurophysiology and the perceptual deficits of individual animals.

Finally, our discoveries on the abnormal spiking noise of V2 neurons $\left(\mathrm{CV}^{2}\right.$ and $\left.\mathrm{m}-\mathrm{FF}\right)$ parallel perceptual noise reported in key psychophysical studies of human amblyopes. As mentioned earlier, the visual system of amlyopes has a high fraction of internal noise (Pelli et al., 2004; Levi, 2013). More specifically, when human amblyopes are tested repeatedly using identical stimuli to quantify perceptual response consistency, they exhibit a high level of internal noise (e.g., abnormal increases in variability or trial-to-trial fluctuations; Levi and Klein, 2003; Levi et al., 2005, 2007, 2008; Li et al., 2008).

In a related matter, it may not be immediately clear how the elevated $\mathrm{CV}^{2}$ (Fig. 5) or abnormal response dynamics (Figs. 2, 3) revealed with high-contrast stimuli in this study can be related to perceptual impairments in human amblyopes. In addition to 

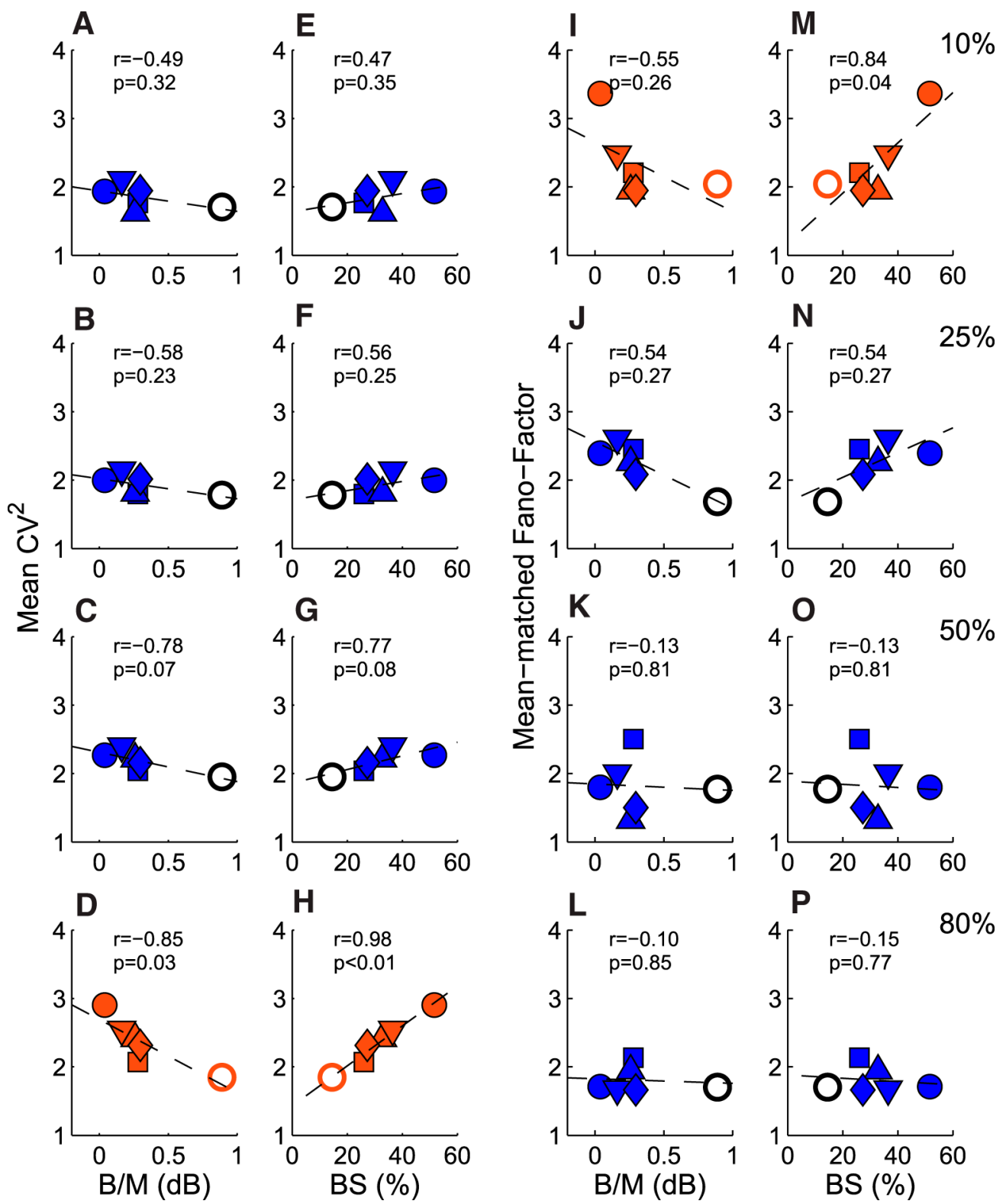

Figure 8. Relationships between spiking noise and suppressive binocular interactions for individual monkeys. $\boldsymbol{A}-\boldsymbol{D}, \mathrm{CV}^{2}$ versus mean $\mathrm{B} / \mathrm{M}$. $\boldsymbol{E}-\boldsymbol{H}, \mathrm{CV}{ }^{2}$ versus prevalence (\%) of binocularly suppressive neurons (BS) for different contrasts. I- $\boldsymbol{L}$, FF versus mean B/M, $\boldsymbol{M}-\boldsymbol{P}$, FF versus prevalence (\%) of binocularly suppressive neurons for different contrasts. Each symbol signifies the mean or percentage value for each experimental monkey. Open circles represent the $\mathrm{B} / \mathrm{M}$ or $\mathrm{CV}^{2}$ values for normal monkeys.

contrast sensitivity loss, amblyopes are known to exhibit a range of more "complex" vision impairments that are often revealed using middle- to high-contrast stimuli: for example, the position uncertainty (Levi and Klein, 1983; Hess and Holliday, 1992), distortion (Sireteanu et al., 1993; Barrett et al., 2003), crowding (Hess and Jacobs, 1979; Levi and Klein, 1985; Levi, 2008), and poor contour integration (Hess and Demanins, 1998; Mussap and Levi, 2000; Chandna et al., 2001; Simmers and Bex, 2004). What is common to these perceptual impairments is that the local estimate of image structures is inaccurate (Levi, 2013) and/or that global image integration is poor or noisy (Simmers and Bex, 2004). In terms of the cortical mechanisms underlying these perceptual deficits, the functional circuitry that compares the spatial relationships between neighboring stimulus elements and accurately integrates local stimulus information over a broad range of space may be compromised in amblyopes. Our study suggests that the excessive irregularities in spike trains $\left(\mathrm{CV}^{2}\right)$ and the ab- normal response dynamics of V2 neurons could adversely affect how various signals are compared and integrated by a network of neurons in V2 and also in downstream visual areas (see below). This could, at least in part, contribute to amblyope's failure to assess accurately the spatial relationships of local stimulus elements over a broad range of space.

\section{Discussion}

\section{Contrast}

In the present study, there were some noteworthy findings in relation to stimulus contrast. First, the perceptual contrast sensitivity loss of individual amblyopic monkeys in this study was largely accounted for by the abnormal contrast threshold and the $C_{50}$ values of their V2 neurons (Fig. 9A,B), providing new evidence for the idea that the neural basis of amblyopia involves deficits in visual areas beyond V1 even for the relatively "simple" 


\section{Contrast}

A Threhold

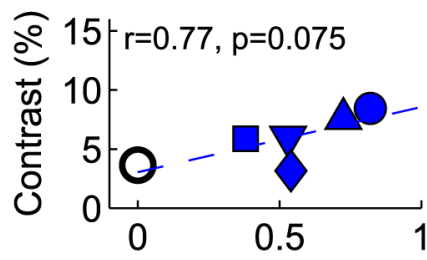

B $\quad \mathrm{C}_{50}$
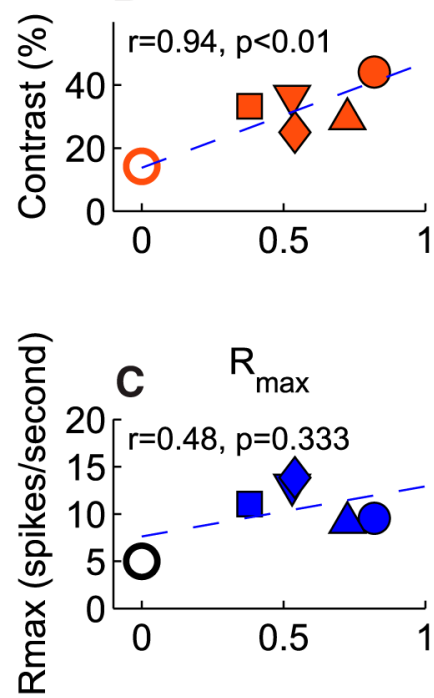

D $\mathrm{n}$

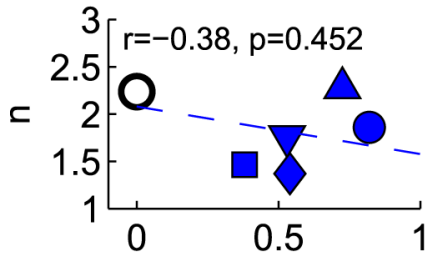

$\mathrm{CV}^{2}$

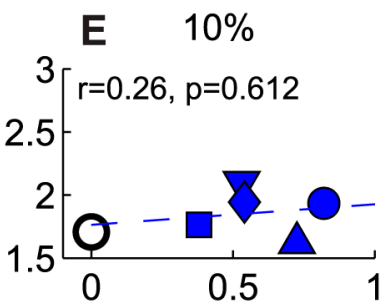

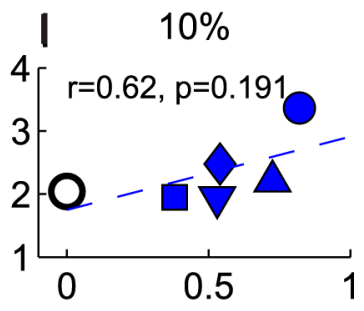
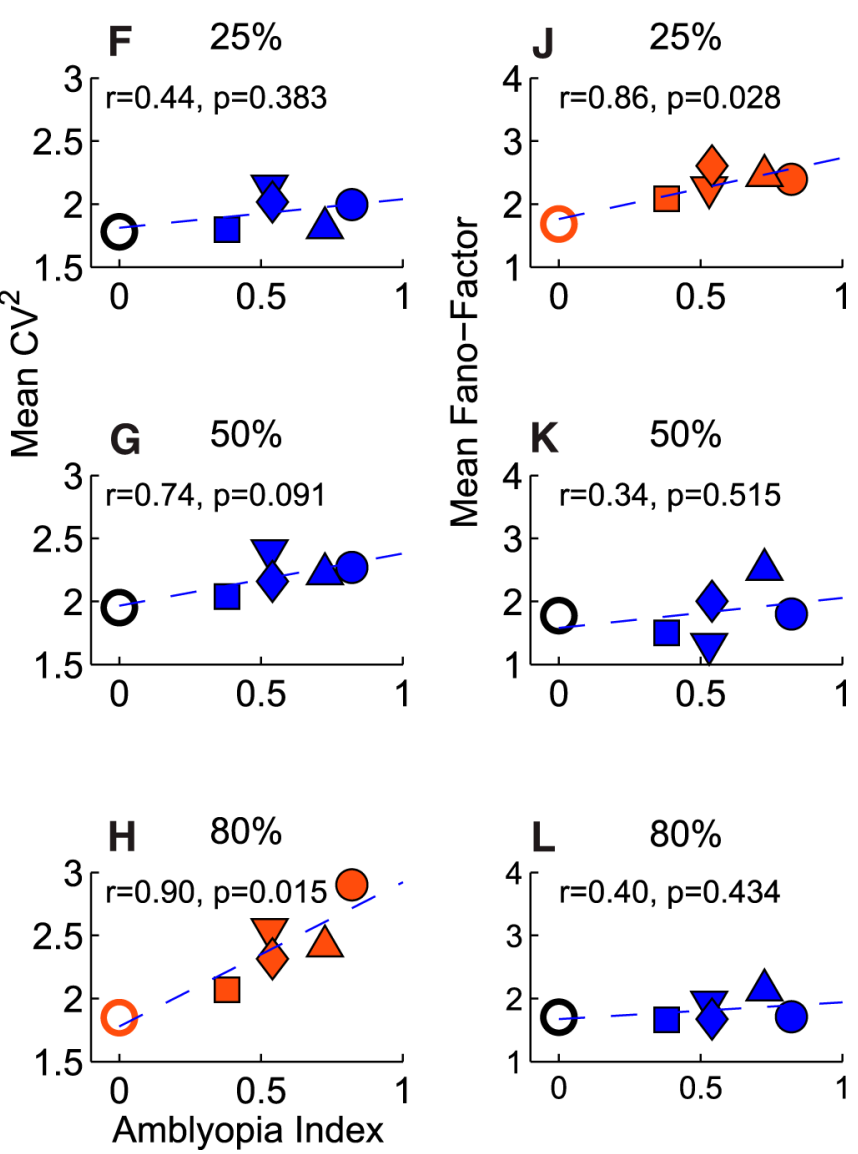

Figure 9. Relationships between the average responses and the depth of amblyopia (amblyopia index) for individual monkeys. $\boldsymbol{A}-\boldsymbol{D}$, Contrast response values versus amblyopia index. $\boldsymbol{E}-\boldsymbol{H}, \mathrm{CV}^{2}$ versus amblyopia index for various contrasts. $\boldsymbol{I}-\boldsymbol{L}$, FF versus amblyopia index for various contrasts.

loss of contrast sensitivity (El-Shamayleh et al., 2010; Bi et al., 2011; Tao et al., 2014; Shooner et al., 2015).

Second, for higher stimulus contrasts (50\% and $80 \%)$, the mean spike count of amblyopic V2 neurons was greater than that in normal neurons and the responses of a substantial number of amblyopic neurons did not saturate at $100 \%$ contrast (Figs. 2, 3E, $4 C$ ). The absence of contrast saturation and the higher median $R_{\max }$ and $C_{50}$ values of amblyopic neurons (Fig. $4 B, C$ ) suggest that the contrast normalization mechanisms may not be operating as efficiently for amblyopic neurons as for normal V2 neurons as a result of experiencing binocular decorrelations of cortical inputs during early development. Because one of the contrast normalization mechanisms in normal cortex is thought to be prolonged inhibition (hyperpolarization) after strong excitation (Carandini and Ferster, 1997; Sanchez-Vives et al., 2000; Keller and Martin, 2015), amblyopic V2 appears to show a weaker inhibitory influence in the local networks that support the monocular receptive fields.

\section{Dynamics}

The altered circuitry in amblyopic V2 can also explain the abnormal response dynamics, specifically, the shorter onset response (i.e., onset latency and time-to-half peak), the absence of an onset transient discharge, and the generally slower response decay (Figs. 2, 3A-D). The shorter onset timing was observed mainly at high contrasts and is closely related to the more vigorous and faster responses of these neurons (Figs. $2 A-C, 3 E$ ). One possibility is that the membrane potential of amblyopic neurons may be more depolarized due to altered cortical circuitry (e.g., reduced inhibitory influence) and this may make the initiation of action 
potentials "easier" before (spontaneous) or during visual stimulation (Faisal et al., 2008; Tiesinga et al., 2008; Mochol et al., 2010).

One of the most striking discoveries in this study was the absence of the onset transient response in amblyopic neurons (Fig. 2), suggesting that the mechanisms that initiate the rapid decline in spiking rate after the peak response are abnormal in amblyopic neurons. According to similar V1 studies in normal animals, such mechanisms include synaptic depression (Müller et al., 2001; Carandini et al., 2002; Boudreau and Ferster, 2005), intrinsic membrane properties (Carandini and Ferster, 1997, 2000; Sanchez-Vives et al., 2000) that are responsible for contrast adaptation (Movshon and Lennie, 1979; Albrecht et al., 1984; Ohzawa et al., 1985; Sclar et al., 1989), and a cortical network of inhibitory neurons (Dealy and Tolhurst, 1974; Ahmed et al., 1997; Boudreau and Ferster, 2005). Although these mechanisms are not mutually exclusive, the altered intrinsic membrane properties and/or a weaker inhibitory network may explain the apparent absence of the onset transient response in our amblyopic V2 neurons. It is noteworthy that this lack of a rapid decline in firing after the onset discharge resulted in an exceptionally wide range of the times to the peak response in amblyopic neurons for high-contrast stimuli (50\% and $80 \%)$. In this respect, it is important to emphasize that the spiking dynamics of V2 neurons in amblyopic primates deviate substantially from that in normal neurons, which could influence information processing adversely in downstream neurons.

\section{Spiking noise $\left(\mathrm{CV}^{2}\right)$}

The spike count irregularity $\left(\mathrm{CV}^{2}\right)$ of amblyopic neurons was abnormally high for the highest contrast gratings (80\%; Fig. $5 A$ ). As mentioned above, the enhanced noise was mainly due to the significant differences between amblyopic and normal neurons in the variance of ISI (Fig. 5B); at higher contrasts, the variance increased in amblyopic neurons, but it decreased in normal neurons, while the differences in the squared mean of ISI, resulting from a high rate of firing, was minimal between the cell groups (Fig. 5C). As a result, the spike count for the $80 \%$ contrast gratings and the $\mathrm{CV}^{2}$ of individual neurons in normal V2 was highly correlated $(r=0.87, p<0.001)$, whereas the correlation for amblyopic neurons (fellow and amblyopic) was minimal (Fig. $5 D$ ). The data suggest that the contrast-dependent abnormality in the spike count irregularity may be directly related to the aberrant contrast normalization mechanisms in amblyopic neurons as described above.

In a related matter, both the higher spike counts and $\mathrm{CV}^{2}$ values of amblyopic neurons for high-contrast visual stimuli were correlated with the $\mathrm{CV}^{2}$ values during robust spontaneous activity (Fig. 5D,F). Spontaneous activity is known to reflect the cortical connectivity and thus interacts with spiking initiated by visual stimulation (for review, see Ringach, 2009). Together, the irregularity of the spontaneous ("ongoing") activity of amblyopic neurons must have had a significant impact on the spike count irregularity during stimulation with high-contrast stimuli. This result suggests that the "functional architecture" of amblyopic V2 was significantly altered during development (Goldberg et al., 2004; Fox et al., 2007; Ringach, 2009). The relatively tight correlation between the mean $\mathrm{CV}^{2}$ values and the prevalence of binocularly suppressive neurons in individual amblyopic monkeys (Fig. $8 H$ ) indicates that the developmental alterations in V2 circuitry may have resulted from abnormal binocular interactions during early development.

\section{Trial-to-trial variability (m-FF)}

The m-FF for amblyopic neurons was abnormally high for lowcontrast stimuli largely due to the high variance in spike counts relative to the mean spike count and that the difference between amblyopic and normal neurons emerged later during the $640 \mathrm{~ms}$ visual stimulation period (Fig. $6 A, B$ ). The latter finding suggests that the abnormal rise in $\mathrm{m}-\mathrm{FF}$ in amblyopic neurons at low contrasts might be due to abnormal contrast adaptation mechanisms. The correlation between m-FFs and the depth of amblyopia (amblyopia index) of individual monkeys (Fig. 9I-L) suggests that, in addition to the contrast sensitivity losses in V2 neurons (Fig. 9A-D), the high trial-to-trial fluctuations in spiking in V2 may be linked to the perceptual losses of our amblyopic monkeys.

The FF during spontaneous activity in amblyopic neurons was correlated with the FF during visual stimulation at lower contrasts (Fig. $6 H$ ), providing further support for the idea that the ongoing activity in the absence of stimulations reflects the network structure and strongly influences the brain activity and behavior initiated by visual stimuli (Fox et al., 2007; Ringach, 2009).

Finally, the finding that the $\mathrm{m}-\mathrm{FF}$ in $\mathrm{V} 2$ neurons in amblyopic monkeys was correlated with the prevalence of binocular suppression (Fig. $8 M-P$ ) suggests that the trial-to-trial variability of V2 neurons may also be linked to early binocular suppression in V1 and V2 (Bi et al., 2011).

\section{Conclusions}

The weak contrast saturation, the apparent lack of the onset transient response (reduced contrast adaptation), the higher than normal and more variable spontaneous activity (reduced local inhibitory influence), and the anomalous contrast-dependent spiking noise in amblyopic neurons all point to one common neural deficit, the abnormal "divisive normalization" in the network (or networks) of amblyopic neurons (Carandini and Heeger, 2011). The frequently cited cortical circuits in normal cortex underlying normalization include the intrinsic lateral connections, the feedback connections, and GABA-mediated local inhibition (Busse et al., 2009; Sit et al., 2009; Carandini and Heeger, 2011; Nassi et al., 2015). The ability of amblyopic V2 neurons to pool local stimulus feature information over an extended area is severely disrupted (Tao et al., 2014). This discovery is consistent with the idea that the circuitry making up the feedforward connections from V1 to V2 and the lateral and/or feedback connections in amblyopic V2 are disorganized and, as mentioned earlier, with the findings that global image integration is poor or noisy in amblyopic primates (Chandna et al., 2001; Kozma and Kiorpes, 2003; Simmers and Bex, 2004; El-Shamayleh et al., 2010).

A key unresolved question is how early chronic monocular defocus leads to "noisy" firing of V2 neurons. One possibility is that early chronic monocular defocus initiates interocular decorrelations of input signals, which results in a high prevalence of binocular suppression in V1 and V2 (Smith et al., 1997; Bi et al., 2011; Tao et al., 2014). Chronic binocular suppression in V1 under daily binocular viewing makes V1 signals to V2 chronically weaker and more variable during early development. This can result in anomalous alterations of the functional architecture of V2 and thus the monocular receptive field properties of individual neurons (excitatory/inhibitory balance; Murphy and Miller, 2009). Understanding the exact nature of the potential link between binocular suppression in V1/V2 and the anomalous alterations of the local circuitry supporting monocular RFs in amblyopic primates requires separate studies. It is important to keep in mind that we do not know whether the spiking noise in 
V2 described here merely reflects similar neuronal noise in V1 or if noise in V1 is "amplified" in V2 until we compare systematically the noise in V1 and V2 for the same amblyopic monkeys.

\section{References}

Ahmed B, Anderson JC, Martin KA, Nelson JC (1997) Map of the synapses onto layer 4 basket cells of the primary visual cortex of the cat. J Comp Neurol 380:230-242. Medline

Albrecht DG, Farrar SB, Hamilton DB (1984) Spatial contrast adaptation characteristics of neurones recorded in the cat's visual cortex. J Physiol 347:713-739. CrossRef Medline

Barrett BT, Pacey IE, Bradley A, Thibos LN, Morrill P (2003) Nonveridical visual perception in human amblyopia. Invest Ophthalmol Vis Sci 44: 1555-1567. CrossRef Medline

Bi H, Zhang B, Tao X, Harwerth RS, Smith EL 3rd, Chino YM (2011) Neuronal responses in visual area V2 (V2) of macaque monkeys with strabismic amblyopia. Cereb Cortex 21:2033-2045. CrossRef Medline

Boudreau CE, Ferster D (2005) Short-term depression in thalamocortical synapses of cat primary visual cortex. J Neurosci 25:7179-7190. CrossRef Medline

Britten KH, Shadlen MN, Newsome WT, Movshon JA (1992) The analysis of visual motion: a comparison of neuronal and psychophysical performance. J Neurosci 12:4745-4765. Medline

Busse L, Wade AR, Carandini M (2009) Representation of concurrent stimuli by population activity in visual cortex. Neuron 64:931-942. CrossRef Medline

Carandini M, Ferster D (1997) A tonic hyperpolarization underlying contrast adaptation in cat visual cortex. Science 276:949-952. CrossRef Medline

Carandini M, Ferster D (2000) Membrane potential and firing rate in cat primary visual cortex. J Neurosci 20:470-484. Medline

Carandini M, Heeger DJ (2011) Normalization as a canonical neural computation. Nat Rev Neurosci 13:51-62. CrossRef Medline

Carandini M, Heeger DJ, Senn W (2002) A synaptic explanation of suppression in visual cortex. J Neurosci 22:10053-10065. Medline

Chandna A, Pennefather PM, Kovács I, Norcia AM (2001) Contour integration deficits in anisometropic amblyopia. Invest Ophthalmol Vis Sci 42: 875-878. Medline

Chino YM, Smith EL 3rd, Hatta S, Cheng H (1997) Postnatal development of binocular disparity sensitivity in neurons of the primate visual cortex. J Neurosci 17:296-307. Medline

Churchland MM, Abbott LF (2012) Two layers of neural variability. Nat Neurosci 15:1472-1474. CrossRef Medline

Churchland MM et al. (2010) Stimulus onset quenches neural variability: a widespread cortical phenomenon. Nat Neurosci 13:369-378. CrossRef Medline

Dealy RS, Tolhurst DJ (1974) Is spatial adaptation an after-effect of prolonged inhibition? J Physiol 241:261-270. CrossRef Medline

El-Shamayleh Y, Kiorpes L, Kohn A, Movshon JA (2010) Visual motion processing by neurons in area MT of macaque monkeys with experimental amblyopia. J Neurosci 30:12198-12209. CrossRef Medline

Faisal AA, Selen LP, Wolpert DM (2008) Noise in the nervous system. Nat Rev Neurosci 9:292-303. CrossRef Medline

Farzin F, Norcia AM (2011) Impaired visual decision-making in individuals with amblyopia. J Vis 11:6-6. CrossRef Medline

Fox MD, Snyder AZ, Vincent JL, Raichle ME (2007) Intrinsic fluctuations within cortical systems account for intertrial variability in human behavior. Neuron 56:171-184. CrossRef Medline

Goldberg JA, Rokni U, Sompolinsky H (2004) Patterns of ongoing activity and the functional architecture of the primary visual cortex. Neuron 42: 489-500. CrossRef Medline

Goris RL, Movshon JA, Simoncelli EP (2014) Partitioning neuronal variability. Nat Neurosci 17:858-865. CrossRef Medline

Hess RF, Demanins R (1998) Contour integration in anisometropic amblyopia. Vision Res 38:889-894. CrossRef Medline

Hess RF, Holliday IE (1992) The spatial localization deficit in amblyopia. Vision Res 32:1319-1339. CrossRef Medline

Hess RF, Jacobs RJ (1979) A preliminary report on acuity and contour interactions across the amblyope's visual field. Vision Res 19:1403-1408. Medline

Keller AJ, Martin KA (2015) Local circuits for contrast normalization and adaptation investigated with two-photon imaging in cat primary visual cortex. J Neurosci 35:10078-10087. CrossRef Medline

Kiorpes L (2006) Visual processing in amblyopia: animal studies. Strabismus 14:3-10. CrossRef Medline

Kiorpes L, Kiper DC, O’Keefe LP, Cavanaugh JR, Movshon JA (1998) Neuronal correlates of amblyopia in the visual cortex of macaque monkeys with experimental strabismus and anisometropia. J Neurosci 18:64116424. Medline

Kohn A, Coen-Cagli R, Kanitscheider I, Pouget A (2016) Correlations and neuronal population information. Annu Rev Neurosci 39:237-256. CrossRef Medline

Kozma P, Kiorpes L (2003) Contour integration in amblyopic monkeys. Vis Neurosci 20:577-588. CrossRef Medline

Levi DM (2008) Crowding-An essential bottleneck for object recognition: a mini-review. Vision Res 48:635-654. CrossRef Medline

Levi DM (2013) Linking assumptions in amblyopia. Vis Neurosci 30:277287. CrossRef Medline

Levi DM, Klein SA (1983) Spatial localization in normal and amblyopic vision. Vision Res 23:1005-1017. CrossRef Medline

Levi DM, Klein SA (1985) Vernier acuity, crowding and amblyopia. Vision Res 25:979-991. CrossRef Medline

Levi DM, Klein SA (2003) Noise provides some new signals about the spatial vision of amblyopes. J Neurosci 23:2522-2526. Medline

Levi DM, Klein SA, Chen I (2005) What is the signal in noise? Vision Res 45:1835-1846. CrossRef Medline

Levi DM, Song S, Pelli DG (2007) Amblyopic reading is crowded. J Vis 7:21.1-21.17. CrossRef Medline

Levi DM, Klein SA, Chen I (2008) What limits performance in the amblyopic visual system: Seeing signals in noise with an amblyopic brain. J Vis $8: 1-23$. CrossRef Medline

Li RW, Klein SA, Levi DM (2008) Prolonged perceptual learning of positional acuity in adult amblyopia: perceptual template returning dynamics. J Neurosci 28:14223-14229. CrossRef Medline

Maruko I, Zhang B, Tao X, Tong J, Smith EL 3rd, Chino YM (2008) Postnatal development of disparity sensitivity in visual area 2 (V2) of macaque monkeys. J Neurophysiol 100:2486-2495. CrossRef Medline

Maunsell JH, Gibson JR (1992) Visual response latencies in striate cortex of the macaque monkey. J Neurophysiol 68:1332-1344. Medline

McKee SP, Levi DM, Movshon JA (2003) The pattern of visual deficits in amblyopia. J Vis 3:380-405. Medline

Mochol G, Wójcik DK, Wypych M, Wróbel A, Waleszczyk WJ (2010) Variability of visual responses of superior colliculus neurons depends on stimulus velocity. J Neurosci 30:3199-3209. CrossRef Medline

Movshon JA, Lennie P (1979) Pattern-selective adaptation in visual cortical neurones. Nature 278:850-852. CrossRef Medline

Müller JR, Metha AB, Krauskopf J, Lennie P (2001) Information conveyed by onset transients in responses of striate cortical neurons. J Neurosci 21:6978-6990. Medline

Murphy BK, Miller KD (2009) Balanced amplification: a new mechanism of selective amplification of neural activity patterns. Neuron 61:635-648. CrossRef Medline

Mussap AJ, Levi DM (2000) Amblyopic deficits in detecting a dotted line in noise. Vision Res 40:3297-3307. CrossRef Medline

Nassi JJ, Avery MC, Cetin AH, Roe AW, Reynolds JH (2015) Optogenetic activation of normalization in alert macaque visual cortex. Neuron 86 : 1504-1517. CrossRef Medline

Nawrot MP, Boucsein C, Rodriguez Molina V, Riehle A, Aertsen A, Rotter S (2008) Measurement of variability dynamics in cortical spike trains. J Neurosci Methods 169:374-390. CrossRef Medline

Ohzawa I, Freeman RD (1986a) The binocular organization of simple cells in the cat's visual cortex. J Neurophysiol 56:221-242. Medline

Ohzawa I, Freeman RD (1986b) The binocular organization of complex cells in the cat's visual cortex. J Neurophysiol 56:243-259. Medline

Ohzawa I, Sclar G, Freeman RD (1985) Contrast gain control in the cat's visual system. J Neurophysiol 54:651-667. Medline

Parker AJ, Newsome WT (1998) Sense and the single neuron: probing the physiology of perception. Annu Rev Neurosci 21:227-277. CrossRef Medline

Pelli DG, Levi DM, Chung ST (2004) Using visual noise to characterize amblyopic letter identification. J Vis 4:904-920. CrossRef Medline

Ringach DL (2009) Spontaneous and driven cortical activity: implications for computation. Curr Opin Neurobiol 19:439-444. CrossRef Medline 
Sanchez-Vives MV, Nowak LG, McCormick DA (2000) Cellular mechanisms of long-lasting adaptation in visual cortical neurons in vitro. J Neurosci 20:4286-4299. Medline

Sclar G, Lennie P, DePriest DD (1989) Contrast adaptation in striate cortex of macaque. Vision Res 29:747-755. CrossRef Medline

Shadlen MN, Newsome WT (1998) The variable discharge of cortical neurons: implications for connectivity, computation, and information coding. J Neurosci 18:3870-3896. Medline

Shooner C, Hallum LE, Kumbhani RD, Ziemba CM, Garcia-Marin V, Kelly JG, Majaj NJ, Movshon JA, Kiorpes L (2015) Population representation of visual information in areas V1 and V2 of amblyopic macaques. Vision Res 114:56-67. CrossRef Medline

Simmers AJ, Bex PJ (2004) The representation of global spatial structure in amblyopia. Vision Res 44:523-533. CrossRef Medline

Sireteanu R, Lagreze WD, Constantinescu DH (1993) Distortion in twodimensional visual space perception in strabismic observers. Vision Res 33:677-690. CrossRef Medline

Sit YF, Chen Y, Geisler WS, Miikkulainen R, Seidemann E (2009) Complex dynamics of $\mathrm{V} 1$ population responses explained by a simple gain-control model. Neuron 64:943-956. CrossRef Medline

Smith EL 3rd, Chino YM, Ni J, Cheng H, Crawford ML, Harwerth RS (1997) Residual binocular interactions in the striate cortex of monkeys reared with abnormal binocular vision. J Neurophysiol 78:1353-1362. Medline
Tao X, Zhang B, Smith EL 3rd, Nishimoto S, Ohzawa I, Chino YM (2012) Local sensitivity to stimulus orientation and spatial frequency within the receptive fields of neurons in visual area 2 of macaque monkeys. J Neurophysiol 107:1094-1110. CrossRef Medline

Tao X, Zhang B, Shen G, Wensveen J, Smith EL 3rd, Nishimoto S, Ohzawa I, Chino YM (2014) Early monocular defocus disrupts the normal development of receptive-field structure in V2 neurons of macaque monkeys. J Neurosci 34:13840-13854. CrossRef Medline

Tiesinga P, Fellous JM, Sejnowski TJ (2008) Regulation of spike timing in visual cortical circuits. Nat Rev Neurosci 9:97-107. CrossRef Medline

Wensveen JM, Harwerth RS, Smith EL 3rd (2003) Binocular deficits associated with early alternating monocular defocus: I. Behavioral observations. J Neurophysiol 90:3001-3011. CrossRef Medline

Wensveen JM, Harwerth RS, Hung LF, Ramamirtham R, Kee CS, Smith EL 3rd (2006) Brief daily periods of unrestricted vision can prevent formdeprivation amblyopia. Invest Ophthalmol Vis Sci 47:2468-2477. Medline

Xu P, Lu ZL, Qiu Z, Zhou Y (2006) Identify mechanisms of amblyopia in Gabor orientation identification with external noise. Vision Res 46:3748 3760. CrossRef Medline

Zhang B, Tao X, Shen G, Smith EL 3rd, Ohzawa I, Chino YM (2013) Receptive-field subfields of V2 neurons in macaque monkeys are adultlike near birth. J Neurosci 33:2639-2649. CrossRef Medline 